\title{
Evaporation from Porous Building Materials and Its Cooling Potential
}

4

\author{
Teresa Diaz Gonçalves, Ph.D. ${ }^{1}$; Vânia Brito²; Filipa Vidigal ${ }^{3}$; Luís Matias, Ph.D. ${ }^{4}$; and Paulina Faria, Ph.D. ${ }^{5}$
}

\begin{abstract}
Evaporative cooling is a traditional strategy to improve summer comfort, which has gained renewed relevance in the context of the transition to a greener economy. Here, the potential for evaporative cooling of common porous building materials, natural stone and ceramic brick, evaluated. The work has relevance also to the protection of built heritage becauseevaporation underlies the problems of dampness and salt crystallization, which are so harmful and frequent in this heritage. It was observed that the drying rate of the materials is, in some cases, higher than the evaporation rate of a free water surface. Surface area measurements by a three-dimensional optical technique suggested, as probable cause of this behavior, that surface irregularity gives rise to a large effective surface of evaporation in the material. Surface temperature measurements by infrared were performed afterward during evaporation experiments outside during a hot summer day in Lisbon. Their results indicate that ordinary building materials can be very efficient evaporative media and, thus, may help in achieving higher energy efficiency while maintaining a simultaneous constructive or architectural function. DOI: 10.1061/(ASCE)MT.1943-5533.0001174. (c) 2014 American Society of Civil Engineers.
\end{abstract}

Author keywords: Porous media; Surface roughness; Fractals; Evaporation; Cooling.

\section{Introduction}

Water is a constant presence in the intricate pore network of traditional building materials, such as mortar, stone, or ceramics. It may have very harmful effects because it functions as a catalyst for deterioration mechanisms, such as sulphate attack, biodeterioration, or salt decay. But it can also have positive effects, for example, when it enables the evaporative cooling of environments.

The evaporative drying of porous materials involves liquid transport toward an evaporation front and vapor transport from that front outward (Sherwood 1929; Scherer 1990). Two main regimes are in general considered, which for a material drying from saturation, correspond to the following main stages (Fig. 1): in Stage I, also called the constant drying rate period (CDRP), there is liquid continuity across the material, and the wet front is located at their surface; the drying rate is constant because drying proceeds under steady-state conditions. Stage II, also called the falling drying rate period (FDRP), starts when the moisture content in the material, and therefore the liquid flow, decreases to a point where it is no longer able to compensate the evaporative demand; and the wet front-begins receding toward the interior of the material.

\footnotetext{
${ }^{1}$ National Laboratory for Civil Engineering (LNEC), Materials Dept., Av. do Brasil 101, 1700-066 Lisbon, Portugal (corresponding author). E-mail: teresag@lnec.pt

${ }^{2}$ National Laboratory for Civil Engineering (LNEC), Materials Dept., Av. do Brasil 101, 1700-066 Lisbon, Portugal. E-mail: vbrito@lnec.pt

${ }^{3}$ Dept. of Civil Engineering, LNEC and Nova Univ. of Lisbon, Caparica Campus, 2829-516 Caparica, Portugal. E-mail: filipavidigal@ hotmail.com

${ }^{4}$ National Laboratory for Civil Engineering (LNEC), Buildings Dept., Av. do Brasil 101, 1700-066 Lisbon, Portugal. E-mail: lmatias@lnec.pt

${ }^{5}$ Nova Univ. of Lisbon, Dept. of Civil Engineering, Caparica Campus, 2829-516 Caparica, Portugal. E-mail: mpr@fct.unl.pt

Note. This manuscript was submitted on January 31,2014; approved on August 5, 2014No Epub Date. Discussion period open until 0, 0; separate discussions must be submitted for individual papers. This paper is part of the Journal of Materials in Civil Engineering, (C) ASCE, ISSN $0899-1561 /(0) / \$ 25.00$.
}

During the CDRP, the drying rate is at its highest value. This value is often assumed to be equal to that of a free water surface, which would be explained by the presence of a liquid film covering the whole surface of the material. However, this idea has been contradicted by researchers, such as Hammecker (1993), Jeannette (1997), Tournier et al. (2000), Rousset-Tournier (2001), and Diaz Gonçalves et al. (2012). These researchers observed that the evaporation rate from porous stones and other building materials during the CDRP was not necessarily equal to the evaporation from a free water surface and, in fact, could even be higher than that. A similar phenomenon was observed by Tang and Etzion (2004) who noticed that, with a low wind velocity, the rate of evaporation from a pond was greater when it was covered with wet tissue.

The possible enhancement of the CDRP drying rate of a porous material in comparison to a flat water surface has a wide range of implications. Indeed, evaporation is often used as a boundary condition in numerical models for moisture transport in porous media, and the most current reference for the CDRP is the evaporation rate of a flat water surface. The study of evaporative processes is also extremely important from more practical perspectives, such as the protection of the arehiteturat heritage. The evaporation rate determines, for example, the height of capillary rise (I'Anson and Hoff 1984), a chronic problem in historical buildings (Massari and Massari 1993). Also, salt decay, one very harmful degradation mechanism that affects this type of building (Charola 2000), happens precisely during evaporative processes by which the solutions increase their concentration until they saturate and eventually crystallize. The study of evaporative drying is therefore fundamental to understand and ultimately develop solutions for these degradation processes. Finally, such study is also relevant from the point of view of sustainability because it is the base of evaporative cooling, one of the oldest strategies for improving summer comfort in hot, dry environments. The wetting of ceramic floors, traditional in Mediterranean countries, such as Portugal, can be mentioned as an example. Evaporative cooling methods rely on the fact that the passage of water from liquid to vapor state involves energy consumption (Matias et al. 2007). These cooling methods have recently gained a new importance and are more and more often incorporated 


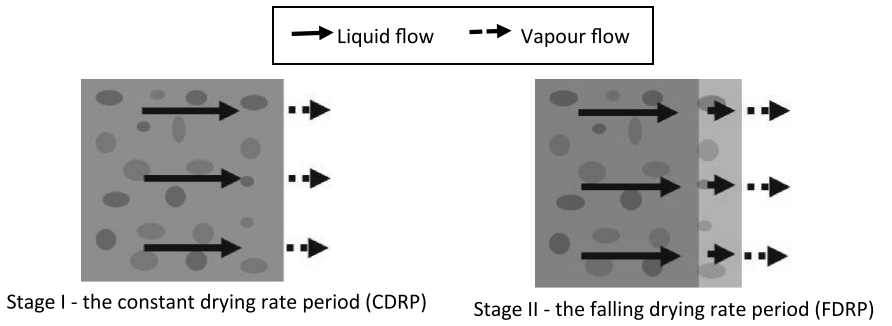

F1:1 Fig. 1. A schematic representation of the two main drying stages of a $\mathrm{F} 1: 2$ porous material

\section{Materials and Methods}

in modern architectural solutions because they can help meet energy-efficiency needs.

In this study, the drying rate of porous building materials during the CDRP is experimentally analyzed. The objective was to investigate the possible enhancement of the CDRP drying rate in comparison to a flat water surface. To support the interpretation of the results, surface area measurements by a three-dimensional (3D) optical technique were carried out. Afterward, the evaporative cooling potential of some of the materials was assessed through the measurement of surface temperature with an infrared thermometer

\section{Materials}

The materials used for determination of the CDRP drying rate are rigid building materials that encompass six natural stones, a red ceramic brick, an air lime/sand mortar, and three calcium silicate materials (Table 1). They were chosen on an exploratory basis for being representative of those used in civil engineering and found in the built heritage and also because they cover a wide range of capillary porosity. This porosity, which corresponds to the natural capacity of the material to absorb water at atmospheric pressure, is also given in Table 1. The pore-size distribution of 10 of the materials is presented in Fig. 2. An Autoscan60 porosimeter from Quantachrome was used, with a pressure range between 0 and $320 \mathrm{MPa}$. The measurements were performed according to ASTM D4404-10 standard (ASTM 2010) and were always replicated. The pore-size distribution of the remaining material, Maastricht limestone, can be found elsewhere (De Clercq et al. 2007). Incoherent materials like sand, sawdust, and cellulose, were used as reference in the evaporative cooling tests (Table 2 ).

\section{Measurement of CDRP Drying Rate}

The CDRP drying rate was measured by means of drying tests (RILEM 1980). These tests followed a method similar to that described in Diaz Gonçalves et al. (2012) except that, here, the experiments lasted just long enough to measure the CDRP drying rate. They were carried out in a conditioned room at $20^{\circ} \mathrm{C}$ and $50 \%$ relative humidity $(\mathrm{RH})$. To eliminate the influence of air velocity, the tests were carried out inside a box. This box is made of acrylic glass, has internal dimensions of $500 \mathrm{~mm} \times 500 \mathrm{~mm} \times 500 \mathrm{~mm}$ and possesses a 70-mm-diameter circular opening at the top to allowfor removing the specimens with minimal perturbation of the internal conditions. The RH inside the box was controlled by means of salts solutions, a desiccant, or simply by leaving it open (Table 3).

Table 1. Rigid Materials Used for Determination of CDRP Drying Rate

\section{CS.LS}

CS.L500

$\mathrm{M}$

MB

CS.B

L

CA

A

$\mathrm{T}$

CB

$\mathrm{CC}$

Calcium silicate board PROMATECT_LS (Promat)
Calcium silicate board PROMATECT_L500 (Promat)
Maastricht limestone
Malta's Globigerina limestone_-Badjda type
Calcium silicate brick VB15 (Silka)
Lecce calcarenite
Ança limestone
Lime mortar (1:3 by volume of air lime and sand)
Solid red ceramic brick (Cerâmica Vale de Gândara, Portugal)
Current Portuguese limestone of intermediate porosity
Current Portuguese limestone of low porosity

Calcium silicate board PROMATECT - LS (Promat)

Maastricht limestone

Malta's Globigerina limestone-Badjda type

Lecce calcarenite

Anç limestone

Lime mortar (1:3 by volume of air lime and sand)

Current Portuguese limestone of intermediate porosity

${ }^{\mathrm{a}}$ The capillary porosity was measured after complete immersion in water for $48 \mathrm{~h}$, following RILEM procedure II.1 (RILEM 1980). Three specimens of each kind were used.
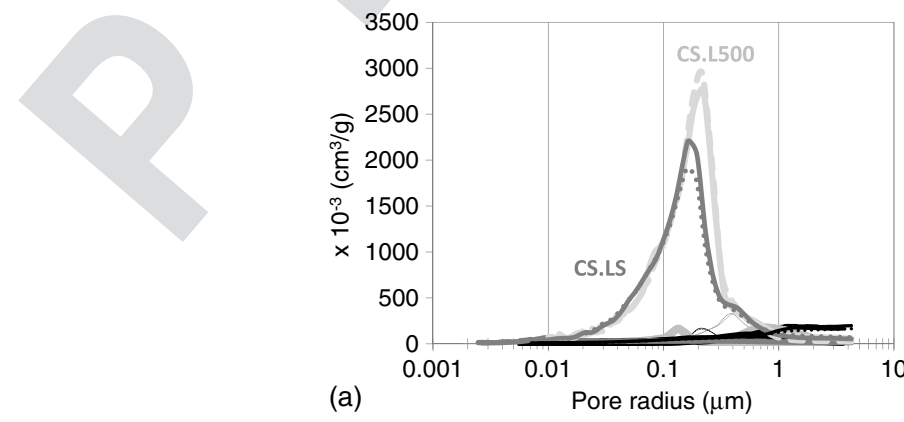

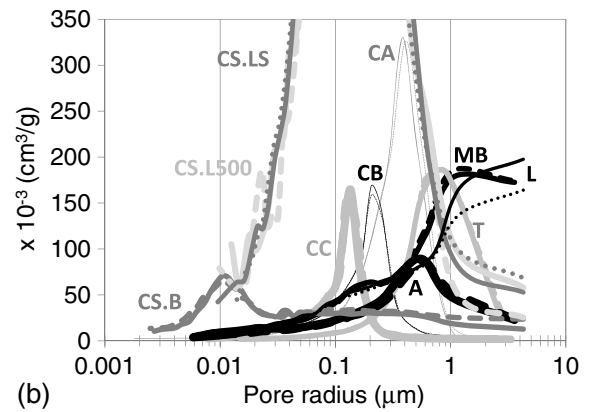

Fig. 2. Pore-size distribution as determined by mercury instrusion porosimetry (MIP) 
Table 2. Incoherent Materials Used as Reference in Evaporative Cooling Tests

$\mathrm{T} 2: 1$

$\mathrm{T} 2: 2$

$\mathrm{T} 2: 3$

$\mathrm{T} 2: 4$

$\mathrm{T} 2: 5$

$\mathrm{T} 2: 6$

\begin{tabular}{lc}
\hline Reference & Description \\
\hline $\mathrm{AF}$ & Fine siliceous sand $0.08-0.16 \mathrm{~mm}$ (fraction $\forall^{\mathrm{a}}$ ) \\
$\mathrm{AM}$ & Medium siliceous sand $0.30-0.50 \mathrm{~mm}$ (fraction $\mathrm{IV}^{\mathrm{a}}$ ) \\
$\mathrm{AG}$ & Coarse siliceous sand $1.60-2.00 \mathrm{~mm}$ (fraetion $\mathrm{I}^{\mathrm{a}}$ ) \\
$\mathrm{S}$ & Sawdust: residual material of a sawmill \\
$\mathrm{C}$ & Cellulose: paper paste from the paper industry; \\
& supplied by Portucel Soporcel
\end{tabular}

${ }^{\text {a} A c c o r d i n g ~ t o ~ E N ~ 196-1 ~(C E N ~ 2005) . ~}$

Table 3. Environmental Conditions during Drying Experiments

T3:2

$\mathrm{T} 3: 3$

$\mathrm{T} 3: 4$

T3:5

$\mathrm{T} 3: 6$

\begin{tabular}{lcc}
\hline & \multicolumn{2}{c}{$\mathrm{RH}(\%)$ at $20^{\circ} \mathrm{C}$} \\
\cline { 2 - 3 } $\mathrm{RH}$ control & Nominal $\mathrm{RH}$ & Actual $\mathrm{RH}_{\mathrm{av}}{ }^{\mathrm{a}}$ \\
\hline $\mathrm{CaCl}_{2}$ (powder) & $0.0^{\mathrm{b}}$ & $25.2 \pm 3.1$ \\
$\mathrm{LiCl}$ (saturated solution) & $12.4^{\mathrm{c}}$ & $44.4 \pm 5.3$ \\
$\mathrm{No} \mathrm{salt}$ (box left open) & 50.0 (as in the lab room) & $66.3 \pm 2.0$ \\
$\mathrm{NaCl}$ (saturated solution) & $75.5^{\mathrm{c}}$ & $79.2 \pm 3.5$ \\
\hline
\end{tabular}

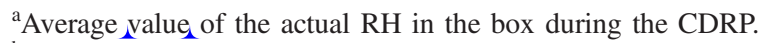

${ }^{\mathrm{b}}$ Data from CEN (2001).

${ }^{\mathrm{c}}$ Data from ASTM (2007).

The specimens were small cubes with a-24-mm edge. The mortar cubes were made using metallic molds. The other specimens were sawed from larger stone blocks, ceramic bricks, calcium silicate brick, or insulation boards. All the cubes were brushed to remove as much stone or brick powder as possible from their surfaces. Then, they were cleaned in an ultrasonic cleaner (model B1200 E-1, Branson Ultrasonics Corporation, United States). Finally, they were laterally sealed with epoxy.

For every condition, the materials and free water surfaces were tested simultaneously. The specimens were first saturated by partial immersion in pure water during three days. Afterward, their bottom surface was sealed with polyethyleneffilm $(\mathrm{PE})$. They were then left to dry and were periodically weighted during $8 \mathrm{~h}$.

Three test specimens of each kind of material were used at every condition, except for four of the-previously tested materials- $(B$, $\mathrm{MB}, \mathrm{CA}$, and $\mathrm{T}_{2}$. In these eases, it was considered reasonable to use only two specimens, as the preceding results were very homogeneous (Diaz Gonçalves et al. 2012). For the free water surfaces, three full petri dishes were always used.

The environmental conditions inside the drying box were continuously monitored by means of a Mikromec Multisens sensor positioned in its center-(Table 3 ). The measurements started before the specimens and petri dishes were placed inside the box and proceeded until after they were removed from it: As seen inFig. 3, both the initial $\mathrm{RH}$ and the final $\mathrm{RH}$ are similar to the nominal $\mathrm{RH}_{\mathbf{c}}$. This show that when the wet materials and petri dishes are not inside the box, the actual RH (eventually) assumed the values expected in each case. The localized perturbations of the RH inside the box were due to the periodic opening of the box and removal of the specimens to weight them. The actual RH considered for this work was the average of the RH measured during the CDRP in each test: $25 \%, 44 \%, 66 \%$, and 79\%, respectively (Table 3 ).

The result of a drying test is a graph depicting the mass of the specimens as function of time (Fig. 4). The drying rate of the specimen, in $\mathrm{g} / \mathrm{h}$, is the slope of the mass-time function. This value is then divided by the area of the top surface of the specimen to obtain the amount of water evaporated per unit area, in $\mathrm{g} /\left(\mathrm{m}^{2}-\mathrm{h}\right)$.

\section{Measurement of Surface Area by Optical Method}

The surface texture of 10 materials (those in Table 1 , except the Maastricht limestone) was studied using the 3D optical measuring instrument Talysurf CLI 1000, by Taylor Hobson. The instrument was equipped with a (noncontact) white light CLA gauge with a vertical range of $3 \mathrm{~mm}$, vertical resolution of $100 \mathrm{~nm}$, lateral resolution of $5 \mu \mathrm{m}$ and measuring slope of $13^{\circ}$ (Taylor Hobson 2009).

The measurements were carried out in $3 \mathrm{D}$ with the highest possible resolution, which corresponds to a spacing of $5 \mu \mathrm{m}$ in both the $\mathrm{X}$ and $\mathrm{Y}$ directions. A velocity of $2 \mathrm{~mm} / \mathrm{s}$ was chosen because it is the highest possible at the selected resolution.

Areal parameter Sdr (ISO 2012) was calculated after the measurements using the Talymap Gold software. Sdr is the developed interfacial area ratio and expresses the percentage of additional surface area contributed by the texture, as compared to the projected area. Using the resampling operator of the Talymap software, Sdr could be calculated for different measurement scales: $5 \mu \mathrm{m}$ (the original measurement step), $10 \mu \mathrm{m}, 20 \mu \mathrm{m}, 50 \mu \mathrm{m}, 100 \mu \mathrm{m}$, and $200 \mu \mathrm{m}$. From the $\mathrm{Sdr}$ value $_{\boldsymbol{k}}$ the relative area (RA) could be
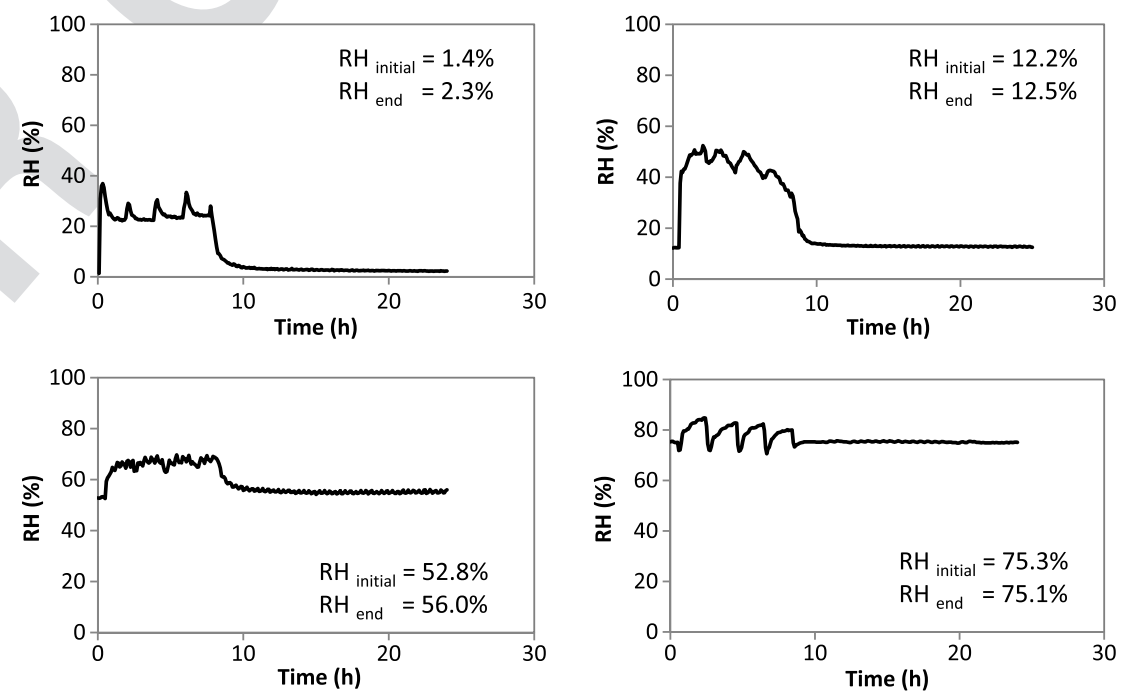

Fig. 3. RH inside the drying box during the experiments 


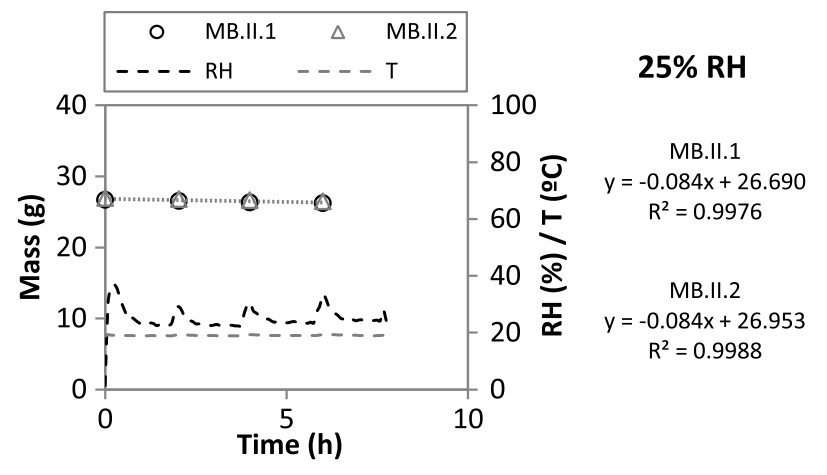

F4:1 Fig. 4. Mass-time drying curves of two specimens of the MB stone, F4:2 and environmental conditions (temperature and $\mathrm{RH}$ ) during the test

determined. RA is a dimensionless quantity that expresses the ratio between the projected surface area A of a material and its developed surface area [Eq. (1)]

$$
R A=\frac{A_{\text {developed }}}{A_{\text {projected }}}=\frac{S d r}{100}+1
$$

\section{Evaporative Cooling Experiments in Real Outdoor Conditions}

The evaporation experiments were undertaken in real outdoor conditions during a hot summer day in Lisbon. One test was carried out under direct sunlight and another in the shade. There were no nearby buildings or heat sources in the location chosen for the test (ANEC Surface temperature was measured with an thermometer Raytek (model MX4PG).

The tests were carried out on five rigid materials, namely calcium silicate CS.L500, Maastricht $\mathrm{M}$ and CB limestones, lime mortar A, and red ceramic brick T (Table 1). Distilled water and several incoherent materials (three grades of -siliceous sand, sawdust and cellulose) were also tested to serve as reference (Table 2).

Cubic specimens of the rigid materials were used with $50-\mathrm{mm}$ edge. For the calcium silicate it was necessary to use samples with a lower height, $35 \mathrm{~mm}$, owing to the dimensions of the original board. The four lateral sides of these specimens were sealed with epoxy. The incoherent materials and water were placed in acrylic boxes with internal dimensions of $50 \mathrm{~mm} \times 50 \mathrm{~mm} \times 50 \mathrm{~mm}$.
The base of these boxes was perforated to allow capillary absorption, and a filter paper was put on the inside-base to avoid material loss.

The materials were by capillary absorption through the base by-means of partial immersion in water for $48 \mathrm{~h}$ in a conditioned room $\left(20^{\circ} \mathrm{C}\right.$ and $\left.50 \% \mathrm{RH}\right)$. After this period, the samples were removed from immersion and its lower face immediately sealed with film to ensure that drying would be unidirectional, taking place only through the upper surface.

The cubes and containers were fit in openings cut in a XPS board with dimensions of $800 \mathrm{~mm} \times 800 \mathrm{~mm} \times 50 \mathrm{~mm}$, as shown in Fig. 5. Two specimens of each material were used, one wet and one dry, as well as two containers (AD1 and AD2) filled with distilled water. The dry materials, which served as a reference for subsequent interpretation of results, were previously dried in an oven during $24 \mathrm{~h}$ at $60^{\circ} \mathrm{C}$, followed by $24 \mathrm{~h}$ in the conditioned room at $20^{\circ} \mathrm{C}$ and $50 \% \mathrm{RH}$. After fitting all the materials and containers for in the XPS board, the assembly was wrapped in PE film to prevent evaporation [Fig. 5(a)]. The water was placed in a closed eontainer. The experimental deviee and the container with water were then transported and left in the selected place (in the sun) at 12 p.m. They remained in these conditions for $1 \mathrm{~h}$ to stabilize their temperature, after which the film was ent the two acrylic containers filled with water.

The surface temperature measurements [Fig. $5(\mathrm{~b})$ ] began immediately and were repeated every $15 \mathrm{~min}$ for $1.5 \mathrm{~h}$. The temperature was measured in the center of the top surface of the specimens, with the positioned perpendicularly and at a distance of $350 \mathrm{~mm}$ from this surface. The environmental conditions (temperature and $\mathrm{RH}$ ) were evaluated with a digital thermohygrometer.

\section{Assessment of the Emissivity}

The infrared (IR) thermometer measures the amount of energy (radiance $\mathrm{E}$, in $\mathrm{W} / \mathrm{m}^{2}$ ) emitted by an object. Then, based on an emissivity value entered by the operator, it calculates the surface temperature of that object through Eq. (2) which is based on Stephan Boltzmann law (Matias 2012)

$$
E=\varepsilon \sigma T^{4}
$$

In this equation, $\varepsilon$ (dimensionless) = the emissivity of the material, which represents the relation between the radiance of the body under examination-and that of a black body (body that absorbs all radiation); $\sigma=$ the Stefan-Boltzmann constant; which takes an absolute value of $5.67 \times 10^{-8} \mathrm{~W} /\left(\mathrm{m}^{2} \mathrm{~K}^{4}\right)$; and $\mathrm{T}=$ the temperature $(\mathrm{K})$.

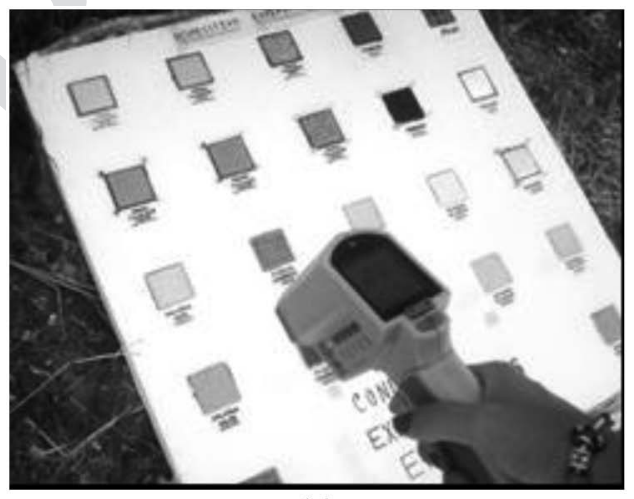

(a)

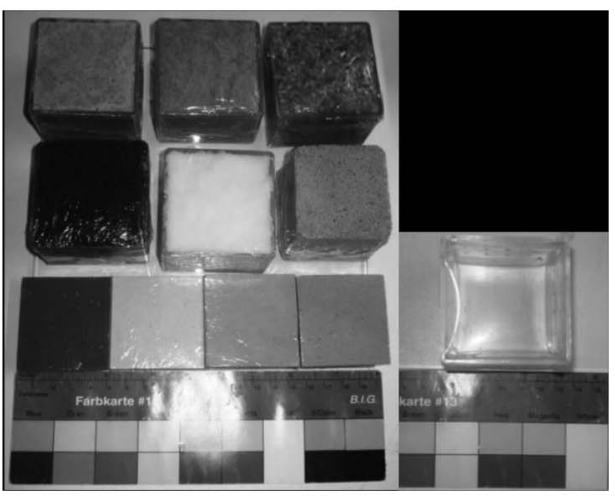

(b)

F5:1 Fig. 5. F5:2 and water-filled container wrapped in PE film 
Table 4. Some Emissivity Values Found in Literature

$\mathrm{T} 4: \mathbb{2}$

$\mathrm{T} 4: 3$

$\mathrm{T} 4: 4$

T4:5

T4:6

T4:7

T4:8

T4:9

T4:10

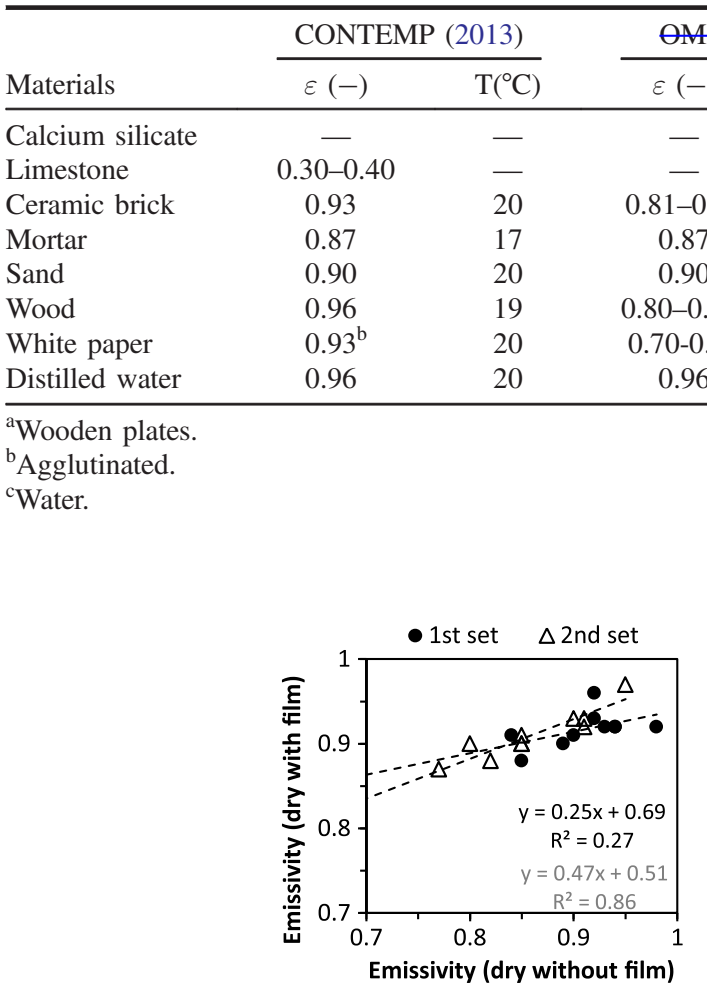
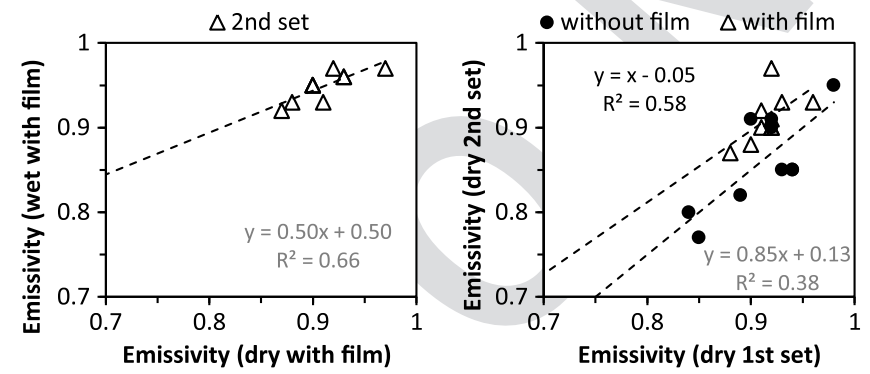

F6:1

F6:2

Fig. 6. Comparison of the measured emissivity values: (a) between materials with or without PE film; (b) between dry and wet materials; (c) among two identical tests on the same materials

For most of the tested materials and also for the water, emissivity values can be found in the literature. These are, however, quite variable from author to author and sometimes given as a range rather than as individual values. Further, they always concern materials in the dry state-(Table-4).

Therefore, it was decided to measure experimentally the emissivity of the present materials and distilled water. This was carried out following the method recommended by the manufacturer of the IR thermometer. The specimens were first left in a conditioned room at $20^{\circ} \mathrm{C}$ and $50 \% \mathrm{RH}$ for several days, so that they were in thermal equilibrium. Then, successive measurements of their surface temperature were performed with the IR thermometer, changing the emissivity until a surface temperature identical to that expected under thermal equilibrium conditions, i.e., $20^{\circ} \mathrm{C}$ (293.15 K) was achieved.

The wet materials and the water-filled container were involved in polyethylene film, as shown in Fig. 5(b), to prevent evaporation because this would lower their surface temperature.

Two sets of measurements were carried out; the results are shown in Table 5 and Fig. 6. As seen, average emissivity values between 0.86 and 0.95 were obtained, with a tendency for having higher values associated with the use of the PE film [Fig. 6(a)], and even higher values with the presence of water in the material [Fig. 6(b)]. The dispersion of results within each test was not very expressive, as seen by the standard deviation values presented in Table 5, which represent a maximum of $7 \%$ in relation to the average values.

However, the repeatability of this method for determining the emissivity was not good, as shown by Fig. 6(c). For this reason, it was decided to adopt a single emissivity value for all the materials (which in fact is the usual procedure). A value of 0.92 was chosen because it is close to the obtained experimental values and also to those found in the literature for this type of materials.

\section{Results and Discussion}

\section{CDRP Drying Rate and Surface Area}

Fig. 7 depicts the variation of the CDRP drying rate (DR) of the materials and water surfaces as a function of the $\mathrm{RH}_{\mathrm{av}}$; which is

Table 5. Experimental Measurement of Emissivity

\begin{tabular}{|c|c|c|c|c|c|}
\hline \multirow[b]{3}{*}{ Materials } & \multicolumn{2}{|c|}{ First test } & \multicolumn{3}{|c|}{ Second test } \\
\hline & \multicolumn{2}{|c|}{ Dry materials } & \multicolumn{2}{|c|}{ Dry materials } & $\begin{array}{l}\text { Wet materials } \\
\text { and water }\end{array}$ \\
\hline & $\begin{array}{l}\text { Without } \\
\text { PE film }\end{array}$ & $\begin{array}{l}\text { With } \\
\text { PE film }\end{array}$ & $\begin{array}{l}\text { Without } \\
\text { PE film }\end{array}$ & & $\begin{array}{l}\text { With } \\
\text { PE film }\end{array}$ \\
\hline $\mathrm{AI}_{2}$ & 0.92 & 0.93 & 0.91 & 0.93 & 0.96 \\
\hline $\mathrm{AIVA}$ & 0.92 & 0.96 & 0.90 & 0.93 & 0.96 \\
\hline$A-V_{2}$ & 0.90 & 0.91 & 0.91 & 0.92 & 0.97 \\
\hline CS L500 & 0.93 & 0.92 & 0.85 & 0.90 & 0.95 \\
\hline $\mathrm{T}$ & 0.94 & 0.92 & 0.85 & 0.91 & 0.93 \\
\hline A & 0.98 & 0.92 & 0.95 & 0.97 & 0.97 \\
\hline $\mathrm{CB}$ & 0.94 & 0.92 & 0.85 & 0.90 & 0.95 \\
\hline M & 0.89 & 0.90 & 0.82 & 0.88 & 0.93 \\
\hline$S$ & 0.85 & 0.88 & 0.77 & 0.87 & 0.92 \\
\hline $\mathrm{C}$ & 0.84 & 0.91 & 0.80 & 0.90 & 0.95 \\
\hline $\mathrm{AD}$ & - & - & - & - & 0.97 \\
\hline Average & 0.91 & 0.92 & 0.86 & 0.91 & $0.95^{\mathrm{a}}$ \\
\hline Standard deviation & 0.04 & 0.02 & 0.06 & 0.03 & $0.02^{\mathrm{a}}$ \\
\hline
\end{tabular}

${ }^{\mathrm{a} C o n s i d e r i n g}$ or not the distilled water. 

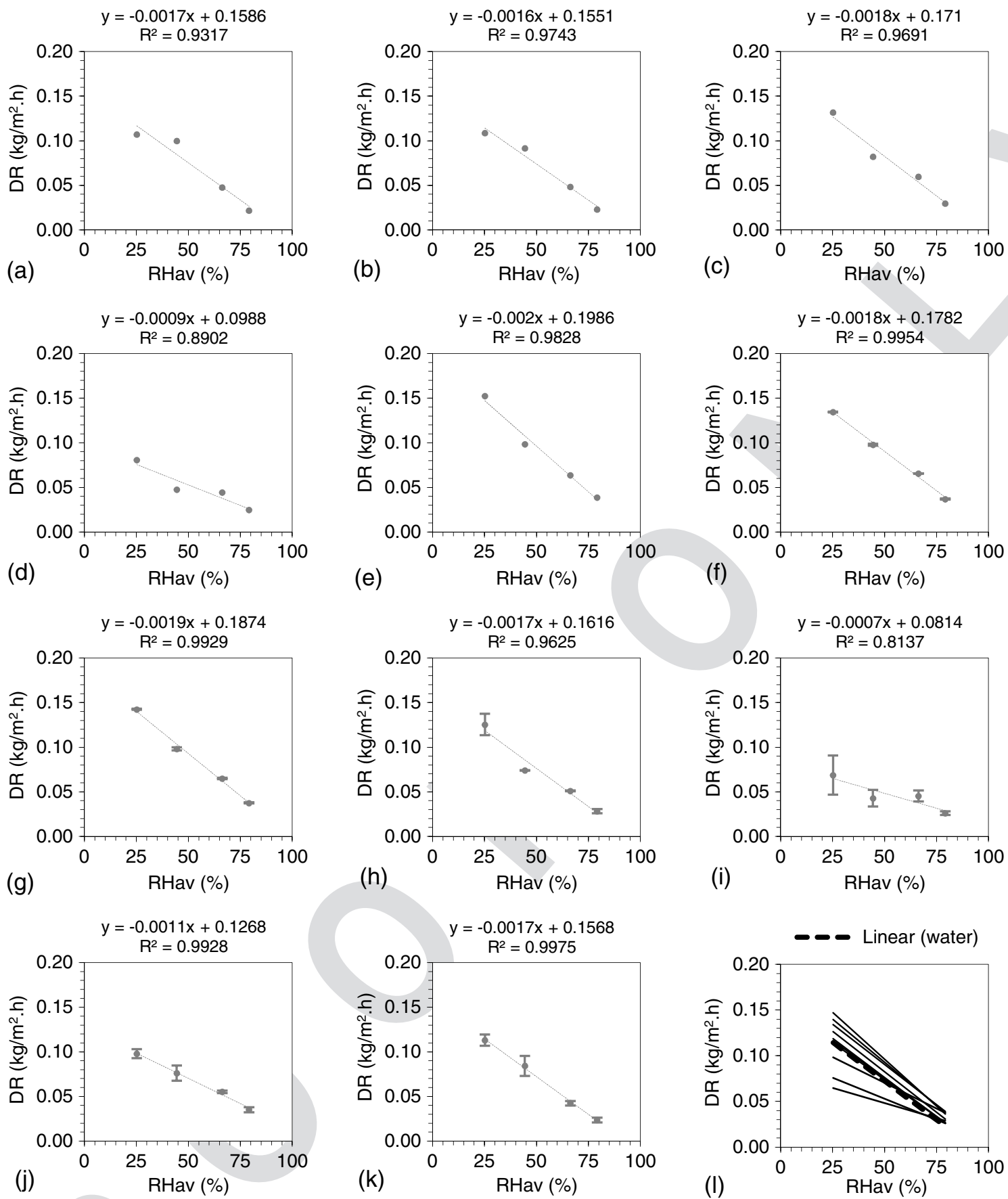

F7:1 12 Fig. 7. Drying rate (DR) from materials during the $\mathrm{CDRP}$ and from free water surfaces as a function of the actual relative humidity $\left(\mathrm{RH}_{\mathrm{av}}\right.$ ); the error

bars correspond to one standard deviation above and one below the average

average of the actual $\mathrm{RH}$ values measured during the CDRP. As seen, the dispersion of the experimental values is generally low. The tendency to have slightly negative values of $\mathrm{DR}$ for $\mathrm{RH}=$ $100 \%$ in some cases suggests that the $\mathrm{RH}_{\mathrm{av}}$ is a slight underestimate of the equivalent $\mathrm{RH}$.

Despite these variation factors, there is an approximately linear relationship between the two quantities. This linearity means that Fick's law [Eq. (3)] is obeyed, which corresponds to an essentially diffusive process (Fig. 8). It also means that the thickness of the stagnant air layer $\delta$ adjacent to the material does not vary with the RH, which happens because the drying tests were performed within a closed box the $_{2}$ thus, air velocity was always close to zero

$$
J=-\Pi \frac{d p}{d x}=-\frac{p_{0}}{100} \Pi \frac{d \mathrm{RH}}{d x}
$$

where $J\left(\mathrm{ML}^{-2} \mathrm{~T}^{-1}\right)=$ the mass flow of water vapor, i.e., the drying rate of the porous material; $\pi(\mathrm{T})=$ the vapor permeability of the layer that water vapor has to cross; $d p / d x\left(\mathrm{MT}^{-2} \mathrm{~L}^{-2}\right)=$ the unidirectional vapor pressure gradient across that layer; and $p_{0}=$ the saturated vapor pressure.

Another relevant observation from Fig. 7 is that the CDRP drying rate of the materials is not necessarily equal to the evaporation rate from the free water surface tested under the same environmental conditions. It can be significantly lower, as it happens for example with the CC limestone in the majority of the conditions, but it 


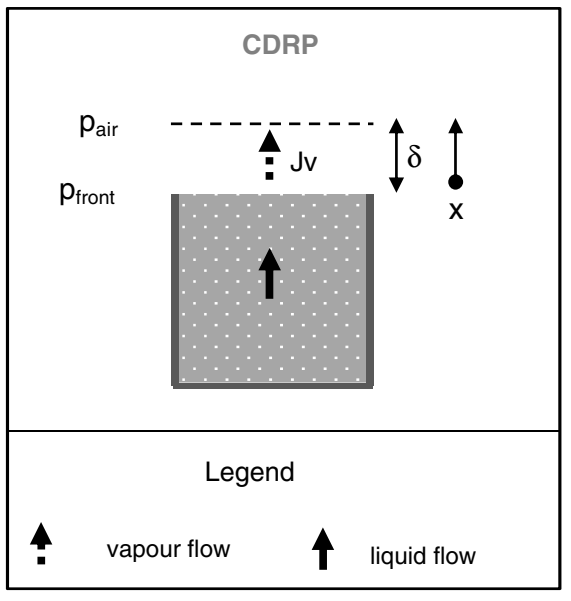

Fig. 8. Representation of CDRP as a diffusive process

can also be higher, as seen in Fig. 7(i). A CDPR drying rate higher than the evaporation rate from a free water surface had already been observed for different types of materials by several authors (Hammecker 1993; Jeannette 1997; Tournier et al. 2000; RoussetTournier 2001; Tang and Etzion 2004; Diaz Gonçalves et al. 2012).

The fact that in some cases the CDRP drying rate is lower than for a free water surface confirms that there is not a liquid film covering the total surface of the materials during the CDRP. If such a film existed, assuming that the liquid possesses the same thermodynamic properties in the pores and in a free surface, the drying rate of the material could perhaps be higher than for the free surface, due to surface irregularity, but it could never be lower.

Tournier et al. (2000) attributed the high CDRP drying rate of porous materials to their surface roughness. This broadly encompasses the fact that in the pores curved menisci are formed (rather than flat water surfaces), as well as the geometrical irregularity of the material surface. However, the concept of (geometrical) surface roughness is when applied to porous materials: straightforward extrapolation of what happens with other simpler types of surfaces, such as metals or plastics, is not possible.

Table 6 depicts the values of the relative area obtained with the optical instrument at different scales, i.e., for different measuring steps. As seen, the RA values vary with the measurement scale. This variation of RA with the measurement scale is graphically depicted in Fig. 9 for the two materials (CS.B and CC) with the larger and smaller RA, respectively. These curves show that RA increases exponentially with seale. They also show that there is a vertical asymptote at point zero of the $\mathrm{X}$-axis.

Table 6. Relative Area of Tested Material Surfaces at Different Measurement Scales (Average Values)

\begin{tabular}{lcccccc}
\hline & \multicolumn{7}{c}{ Measurement scale $(\mu \mathrm{m})$} \\
\cline { 2 - 7 } Material & 5 & 10 & 20 & 50 & 100 & 200 \\
\hline CS.LS & 2.48 & 1.58 & 1.34 & 1.14 & 1.06 & 1.02 \\
CS.L500 & 1.81 & 1.33 & 1.19 & 1.08 & 1.03 & 1.01 \\
MB & 1.69 & 1.28 & 1.19 & 1.12 & 1.06 & 1.02 \\
CS.B & 2.88 & 1.77 & 1.51 & 1.31 & 1.19 & 1.10 \\
L & 1.68 & 1.27 & 1.19 & 1.12 & 1.07 & 1.03 \\
CA & 1.22 & 1.08 & 1.06 & 1.03 & 1.02 & 1.01 \\
A & 2.33 & 1.59 & 1.37 & 1.26 & 1.23 & 1.17 \\
T & 1.29 & 1.12 & 1.07 & 1.03 & 1.02 & 1.01 \\
CB & 1.25 & 1.10 & 1.07 & 1.04 & 1.02 & 1.01 \\
CC & 1.22 & 1.09 & 1.05 & 1.03 & 1.01 & 1.00 \\
\hline
\end{tabular}

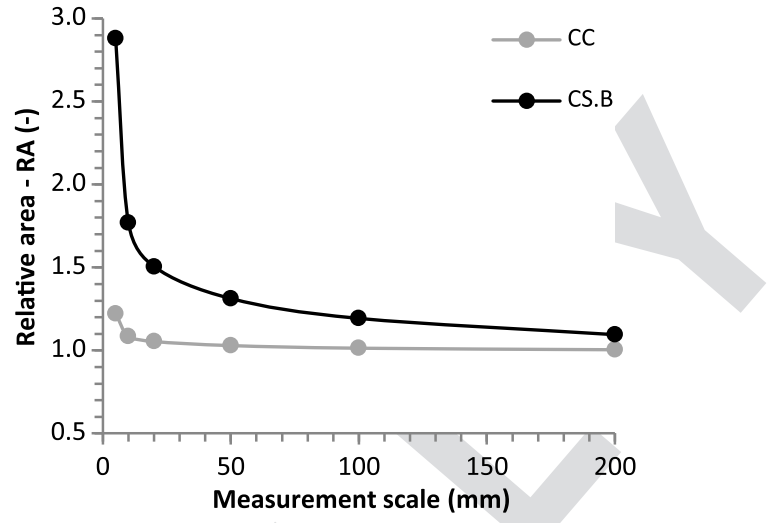

Fig. 9. Relative area (RA) of the surface of two CS.B and CC specimens as a function of the measurement scale

These features indicate that the measured surfaces have fractal properties (Mandelbrot 1967, 1998). A fractal surface is an irregular surface with noninteger dimension between 2 (the Euclidian dimension of a plane) and 3 (the Euclidian dimension of a volume). Several authors have recognized and studied the fractal character of the pore space of natural and artificial porous building materials, such as natural stone (Katz and Thompson 1985; Bernal and Belo 2001), mortars (Arandigoyen et al. 2005; Arandigoyen and Alvarez 2006), or ceramic brick (Benavente et al. 2006). However, this concept has not been fully assimilated by civil engineering.

Due to the topological complexity of the pore space, a higher effective surface of evaporation is therefore-a likely explanation for the high CDRP drying rate depicted by some of the tested materials.

In Fig. 10, the CDRP drying rate is shown as a function of capillary porosity. Point $(0,0)$ is attributed to a theoretical material with $0 \%$ porosity. Since it is admitted that surface irregularity derives from the presence of pores, this theoretical material would be totally flat. As can be seen in the figure, when the two calcium silicate materials with higher porosity are considered, the relationship between the CDRP drying rate and capillary porosity cannot be described by a linear function. Instead, a parabolic function may, for example, be used as a first-order approximation. This means that the CDRP drying rate will increase with increasing porosity but only up to a certain value. Any further rise in the porosity will result, rather, in a decrease of the drying rate. At a certain point, the situation of a free water surface is reached, which corresponds to the maximum possible porosity $(P=1)$. This behavior is due the mentioned-variation of the complexity of the physical surface (which is null for the two extremes $(P=0$ and $P=1)$ and higher for the intermediate situations $(P \downarrow 0,1[)$. However, it is important mention that a clear correlation between the CDRP evaporation rate and the RA values measured with the profilometer was not found. The reason could be the faet that RA varies with the measurement scale and the scale of interest is not necessarily the same for the different materials. Another reason could be that menisci curvature is also relevant in terms of effective surface of evaporation. These subjects clearly require further investigation.

\section{Surface Temperature during Drying}

Figs. 11 and 12 present the surface temperatures measured during the evaporation experiments performed in the shadow and under the sun, respectively. The first ebvious-observation is that the wet materials depict surface temperatures well below those of the dry materials, due to the evaporative cooling-effect.
F9:1

F9:2
326

327

328

329

330

331

332

333

334

335

336

337

338

339

340

341

342

343

344

345

346

347

348

349

350

351

352

353

354

355

356

357

358

359

360

361

362 

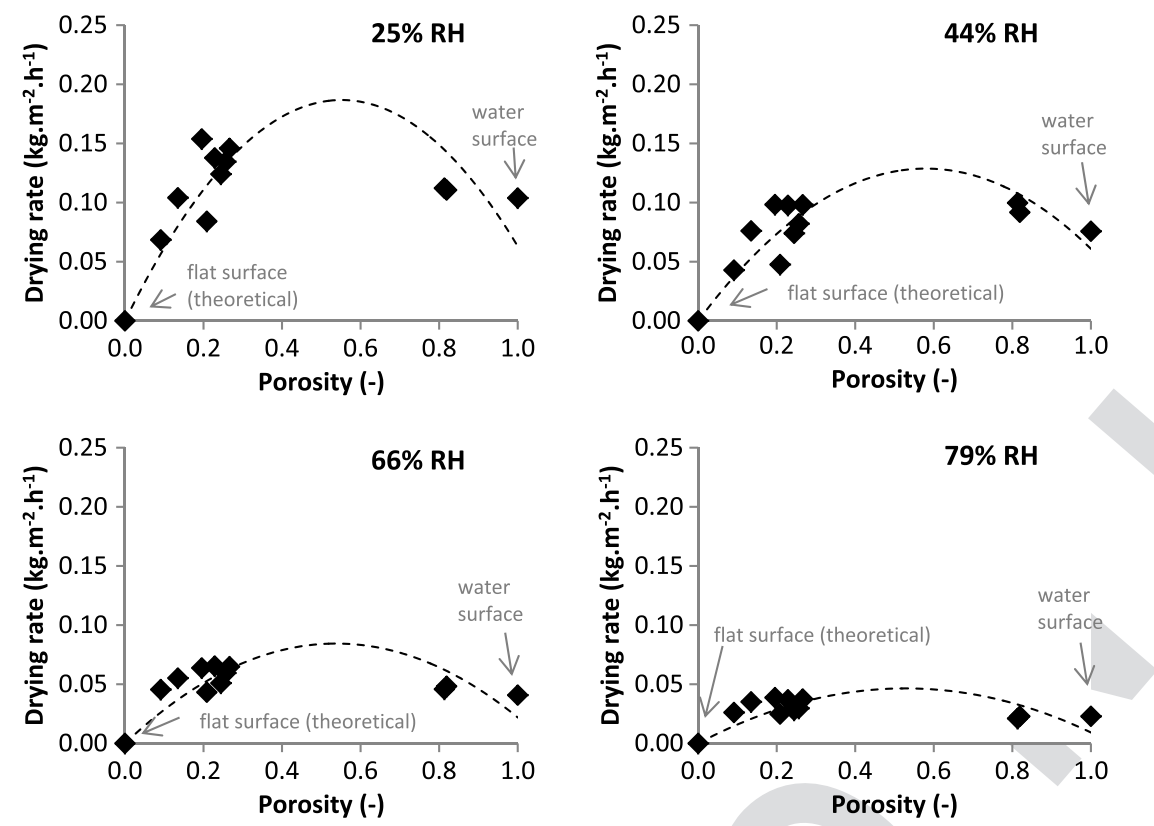

F10:1

F10:2

Fig. 10. Variation of the CDRP evaporation rate with the capillary porosity. The free water surface is considered a material with $100 \%$ porosity; point $(0,0)$ is attributed to a theoretical material with $0 \%$ porosity and, thus, perfectly flat
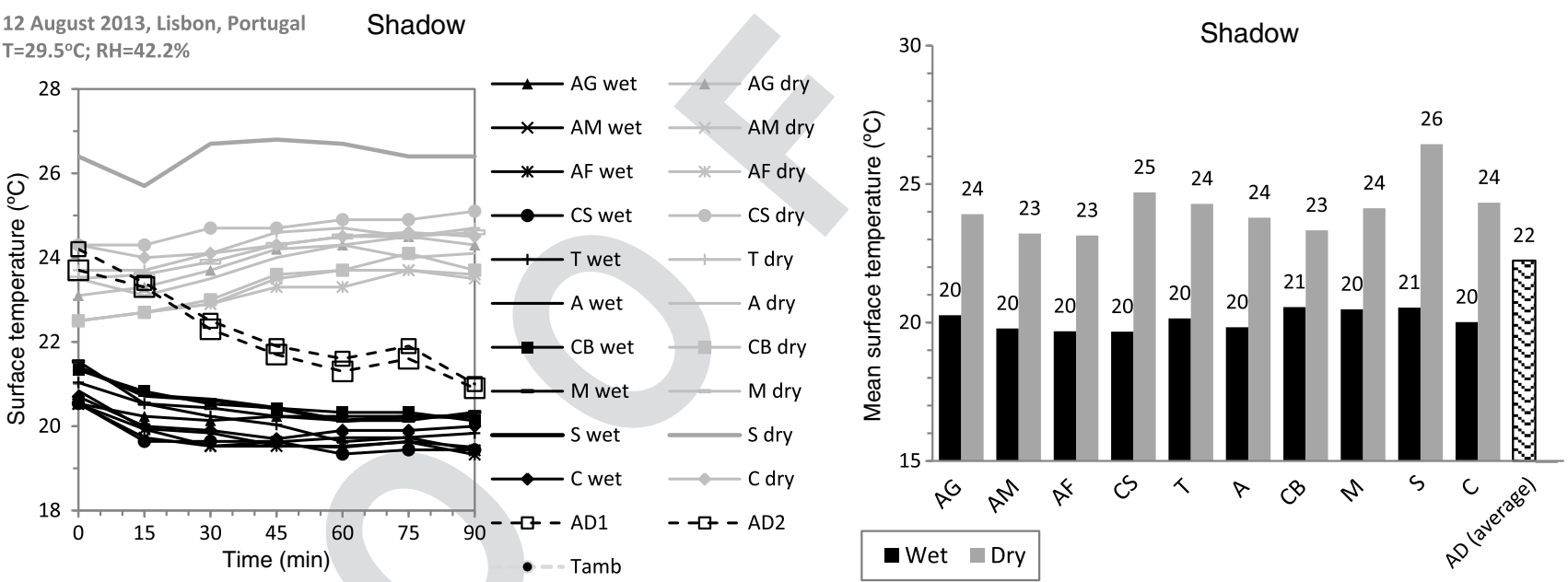

Fig. 11. Surface temperatures measured in shadow

In the shade (Fig. 11), the wet building materials achieve lower surface temperatures than the free water surface (AD) and depict no significant difference in relation to, for example, cellulose (C), which is a product typically used in evaporative cooling devices.

Under the sun (Fig. 12), the situation is different. The brick (T), the coarse sand (AG), the mortar (A), and the sawdust (S) provide, in this case, surface temperatures of $1.2^{\circ} \mathrm{C}$ to $6.3^{\circ} \mathrm{C}$ higher than the free water surface (AD). However, one of the limestones (M), the calcium silicate (CS), and two sands (AM and AF), achieve surface temperatures of $1.7^{\circ} \mathrm{C}$ to $2.8^{\circ} \mathrm{C}$ lower than the free water surface, although about $2.0^{\circ} \mathrm{C}$ to $3.1^{\circ} \mathrm{C}$ higher than cellulose (C).

These results indicate, therefore, that ordinary building materials have interesting evaporative cooling potential. In the future, it would be useful to investigate how much the heat capacity of the materials and their coefficient of solar absorption contribute to the differences among them. It would also be important in the future to obtain more accurate emissivity data for the range of temperatures of interest, as emissivity may also depend on temperature. Such knowledge would allow developing a numerical model to support the development of evaporative cooling systems.

\section{Conclusions and Perspectives}

It was experimentally observed that the drying rate during the CDRP-from porous building materials, such as natural stone or ceramic brick, can be very high. In some cases it may even overcome the evaporation rate from a free water surface subjected to similar environmental conditions. This high drying rate is probably due to the fractal character of the evaporating surface and to menisci curvature. Both features enhance the effective surface of evaporation-in the materiat. 
09 August 2013, Lisbon, Portugal

$\mathrm{T}=34.8^{\circ} \mathrm{C} ; \mathrm{RH}=18.4 \%$

Sun

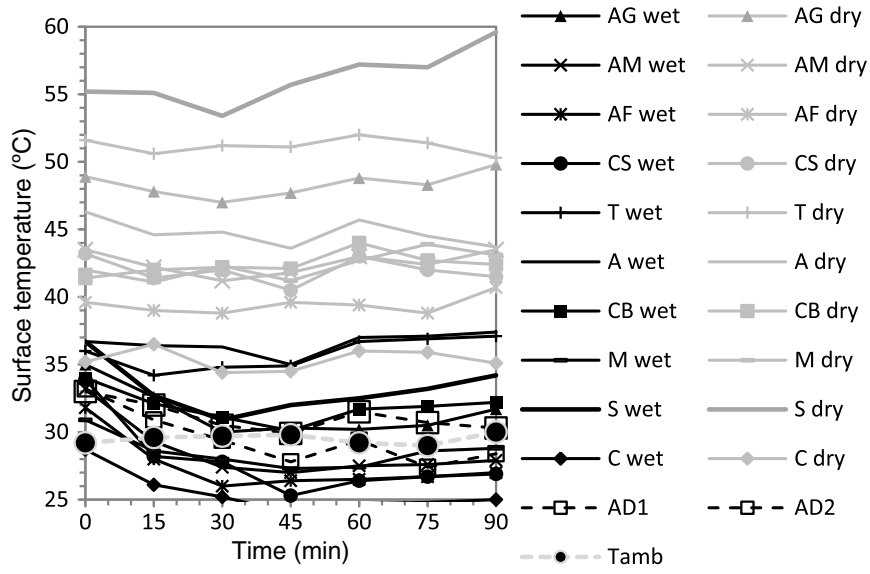

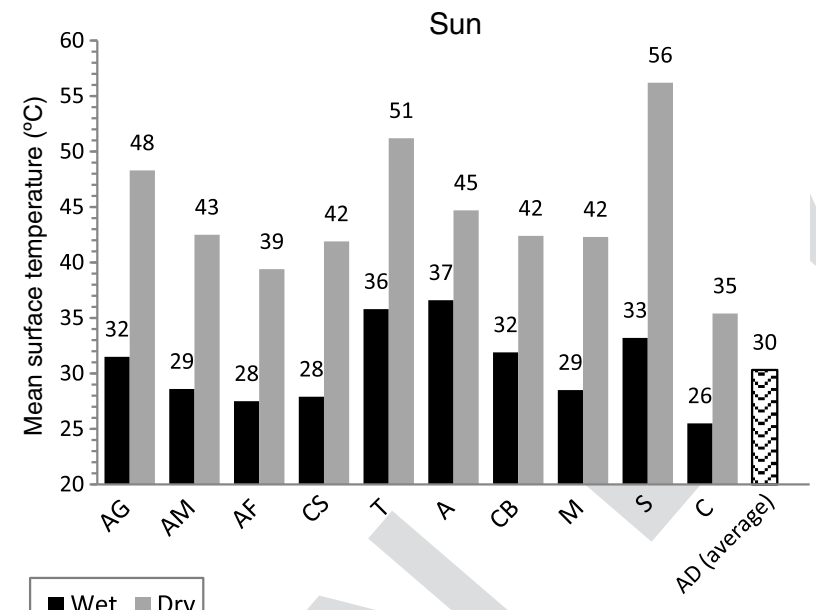

Wet Dry

Fig. 12. Surface temperatures measured under the sun surface. function.

\section{Acknowledgments}

Due to their high CDRP drying rate, porous building materials a high potential for evaporative cooling, which is in accordance with traditional uses in hot, dry climates, such as the wetting of ceramic tiles during summer in Mediterranean countries. This was confirmed experimentally, by means of evaporative cooling experiments performed in the exterior, during a hot summer day in Lisbon. The dry materials achieved high surface temperature, especially in the sun where some materials reached more than $50^{\circ} \mathrm{C}$. However, during drying, their surface temperature dropped on average as much as $10^{\circ} \mathrm{C}$ to $15^{\circ} \mathrm{C}$. The surface temperature of the wet materials achieved values similar (in the sun) or even lower (in the shadow) than that of a free water

This article is expected to contribute to a better assimilation by civil engineering disciplines of the idea that the surface morphology of ordinary porous building materials, such as brick or natural stone, has a fractal multiscale character that affects the way they interact with the environment. Moreover, the obtained experimental results confirm that these materials may be used in efficient evaporative cooling systems for low energy-consuming buildings. They may, thus, help to meet the current needs for energy efficiency while maintaining a simultaneous constructive or architectural

This work was funded by the Portuguese Foundation for Science and Technology (FCT) under the research project DRYMASS (ref. PTDC/ECM/100553/2008). Vânia Brito was supported by a research grant provided under this project. The authors are thankful to Leo Pel (TU/e) and José Delgado Rodrigues (LNEC) for their useful advice on different aspects of the study, and to LNEC technicians Luís Nunes and José Costa who helped on the experimental work. Thanks also to Jo Ann Cassar (University of Malta) for the Malta's Globigerina limestone-samples, to Cerâmica do Vale de Gândara for the red ceramic brick, to Cristovão Soares (Tria) for calcium silicate boards, to James Diamond (Ytong) for calcium silicate bricks, to José Cruz (Lusical) for the hydrated air-lime powder used on the lime mortar, to Patricia Castellano Rodrigues (Portucel Soporcel) for the supply of the-paper paste, and to Pedro

\section{References}

Arandigoyen, M., and Alvarez, J. I. (2006). "Blended pastes of cement and lime: Pore structure and capillary porosity.” Appl. Surf. Sci., 252(20), $7562-7571$.

Arandigoyen, M., Pérez Bernal, J. L., Bello López, M. A., and Alvarez, J. I. (2005). "Lime-pastes with different kneading water: Pore structure and capillary porosity." Appl. Surf. Sci., 252(5), 1449-1459.

ASTM. (2007). "Standard practice for maintaining constant relative humidity by means of aqueous solutions." E104-02, West Conshohocken, PA.

ASTM. (2010). "Test method for determination of pore volume and pore volume distribution of soil and rock by Mercury Intrusion Porosimetry." D4404-10, West Conshohocken, PA.

Benavente, D., Linares-Fernández, L., Cultrone, G., and Sebastián, E. (2006). "Influence of microstructure on the resistance to salt crystallisation damage in brick." Mater. Struct., 39(1), 105-113.

Bernal, J. L. P., and Bello, M. A. (2001). "Fractal geometry and mercury porosimetry comparison and application of proposed models on building stones." Appl. Surf. Sci., 185(1-2), 99-107.

CEN. (2001). "Hygrothermal performance of building materials and products-Determination of water vapour transmission properties." EN ISO 12572:2001, Brussels, Belgium.

CEN. (2005). "Methods of testing cement-Part 1: Determination of strength." CSN EN 196-1, Brussels, Belgium.

Charola, A. E. (2000). "Salts in the deterioration of porous materials: An overview." J. Am. Inst. Conserv., 39(3), 327-343.

CONTEMP- (2013). "Adendo: Tabelas de Emissividade." 〈http://www .contemp.com.br/downloads/pdf/Tabela_de_Emissividades.pdf $\rangle$ (Sep. 16, 2013).

De Clercq, H., De Zanche, S., and Biscontin, G. (2007). "TEOS and time: The influence of application schedules on the effectiveness of ethyl silicate based consolidants." Restor. Build. Monuments, 13(5), 305-318.

Diaz Gonçalves, T., Brito, V., and Pel, L. (2012). "Water vapor emission from rigid mesoporous materials during the constant drying rate period.” Dry. Technol., 30(5), 462-474.

FLIR Systems. (2009). "FLIR reporter professional. Manual-del Usuarie." thttp://support.flir.em/DreDownload/Assets/46/Spanish/1558568 \$a401.pdfil (Sep. 16, 2013).

Hammecker, C. (1993). "Importance des transferts d'eau dans la dégradation des pierres en œuvre." Thèse de doctorat, Université Louis Pasteur, Strasbourg, France.

I'Anson, S. J., and Hoff, W. D. (1984). "Water movement in porous building materials-VIII. Effects of evaporative drying on height of capillary rise equilibrium in walls." Build. Environ., 21(3-4), 195-200.

ISO. (2012). "Geometrical product specifications (GPS). Surface texture: Areal-Part 2: Terms, definitions and surface texture parameters." ISO 25178-2. 
Jeannette, D. (1997). "Structures de porosité, mécanismes de transfert des solutions et principales altérations des roches des monuments." La Pietra dei Monumenti in Ambiente Fisico e Culturale, R. A. Lefèvre, ed., European Univ. Centre for Cultural Heritage, Ravello, 49-77.

Katz, A. J., and Thompson, A. H. (1985). "Fractal sandstone pores: Implications for conductivity and pore formation." Phys. Rev. Lett., 54(12), $1325-1328$.

Mandelbrot, B. (1967). "How long is the coast of Britain? Statistical selfsimilarity and fractional dimension." Science, 156(3775), 636-638.

Mandelbrot, B. (1998). Objectos fractais, Gradiva, Lisboa.

Massari, G., and Massari, I. (1993). Damp buildings: Old and new, ICCROM, Rome.

Matias, L. (2012). "Thermography." Testing techniques for structures inspection, Duratinet Course, LNEC, Lisbon, Portugal.

Matias, L., Vilhena, A., Cristian, A., Santos, C., and Veiga, M. (2007). "Laboratory thermographic analysis of masonry specimens. Capillarity and drying." Proc., 7th Int. Symp. Conservation of Monuments in the Mediterranean Basin, Orléans.

OMEGA. (2013). "Table of total emissivity." Hhttp://wwomacomt temperare/Z/pdf/z088 089.pdf) (Sep. 16, 2013).
RAYTEK. (2004). "High performance infrared thermometer." 〈http://www .instrumart.com/assets/MX4_manual.pdf) (Sep. 16, 2013).

RILEM TC 25-PEM. (1980). "Recommended tests to measure the deterioration of stone and to assess the effectiveness of treatment methods." Mater. Struct., 13, 175-253.

Rousset-Tournier, B. (2001). "Transferts par capillarité et évaporation dans des roches. Rôle des structures de porosité." Thèse de doctorat, Université Louis Pasteur, Strasbourg, France.

Scherer, G. W. (1990). "Theory of drying." J. Am. Ceram. Soc., 73(1), 3-14.

Sherwood, T. K. (1929). “The drying of solids II.” Ind. Eng. Chem., 21(10), 976-980.

Tang, R., and Etzion, Y. (2004). "Comparative studies on the water evaporation rate from a wetted surface and that from a free water surface." Build. Environ., 39(1), 77-86.

Taylor Hobson. (2009). "Talysurf CLI: 3D surface profiling systems." 〈http://www.f-di.hu/cli_systems.pdf〉 (Nov. 13, 2013).

Tournier, B., Jeannette, D., and Destrigneville, C. (2000). "Stone drying: An approach of the effective evaporating surface area." Proc., 9th Int. Congress on Deterioration and Conservation of Stone, Venice. 


\section{Queries}

1. Please provide the ASCE Membership Grades for the authors who are members.

2. NEW! ASCE Open Access: Authors may choose to publish their papers through ASCE Open Access, making the paper freely available to all readers via the ASCE Library website. ASCE Open Access papers will be published under the Creative CommonsAttribution Only (CC-BY) License. The fee for this service is \$1750, and must be paid prior to publication. If you indicate Yes, you will receive a follow-up message with payment instructions. If you indicate No, your paper will be published in the typical subscribed-access section of the Journal.

3. Please check and confirm the heading levels are ok in this article.

4. Please check and confirm edits made in Tables. 1-6 are ok.

5. Please define the abbreviations $\mathrm{B}, \mathrm{MB}, \mathrm{CA}$, and $\mathrm{T}$ on first reference.

6. Is the word "Areal" correct?

7. Please add the Talymap Gold software to the references list.

8. Please spell out LNEC on first reference.

9. The citation (Janssens (2003) mentioned in this sentence is not present in the References list. Please provide the full details for (Janssens (2003), and we will insert it in the References list and link it to this citation.

10. We have changed the underlined values to bold. Please provide significance for bold values in Table 5 .

11. Please check and confirm the layout of Table 5 is ok

12. Please provide part label captions for Fig. 7.

13. Is the word "puting" correct in the acknowledgments?

14. Issue number '20' has been inserted in this reference. Please check and confirm the edit made here.

15. Issue number ' 5 ' has been inserted in this reference. Please check and confirm the edit made here.

16. A check of online databases year found in this reference. Please Add year '2007'.

17. Issue number '1' has been inserted in this reference. Please check and confirm the edit made here.

18. Issue number '1-2' has been inserted in this reference. Please check and confirm the edit made here.

19. Issue number ' 3 ' has been inserted in this reference. Please check and confirm the edit made here.

20. Please provide english translation for ref. CONTEMP.

21. This query was generated by an automatic reference checking system. This reference (De Clercq et al. 2007) could not be located in the databases used by the system. While the reference may be correct, we ask that you check it so we can provide as many links to the referenced articles as possible.

22. Issue number ' 5 ' has been inserted in this reference. Please check and confirm the edit made here.

23. Please provide english translation for ref. Hammecker (1993).

24. This query was generated by an automatic reference checking system. This reference (I'Anson and Hoff 1984) could not be located in the databases used by the system. While the reference may be correct, we ask that you check it so we can provide as many links to the referenced articles as possible.

25. Please provide location of publisher for ref. ISO (2012). 
26. Please provide country name for the Jeannette (1997) reference.

27. Please provide english translation for ref. Jeannette (1997).

28. Issue number '12' has been inserted in this reference. Please check and confirm the edit made here.

29. Issue number ' 3775 ' has been inserted in this reference. Please check and confirm the edit made here.

30. Please provide english translation for ref. Mandelbrot (1998).

31. Please provide the publisher or sponsor name and location (not the conference location) for the reference Matias et al. (2007).

32. This query was generated by an automatic reference checking system. This reference (RILEM 1980) could not be located in the databases used by the system. While the reference may be correct, we ask that you check it so we can provide as many links to the referenced articles as possible.

33. Please provide issue number for the RILEM (1980) reference.

34. Please provide english translation for ref. Rousset-Tournier 2001.

35. Issue number ' 1 ' has been inserted in this reference. Please check and confirm the edit made here.

36. Issue number '10' has been inserted in this reference. Please check and confirm the edit made here.

37. Issue number ' 1 ' has been inserted in this reference. Please check and confirm the edit made here.

38. Please provide the publisher or sponsor name and location (not the conference location) for the reference Tournier et al. (2000). 